\title{
Multicriteria analysis measurement of the road transport corridor impact on the environment
}

\author{
D. Micevičienè ${ }^{1}, \check{Z}$. Bazaras ${ }^{1}$, J. Ciburiene ${ }^{2} \&$ V. Boguslauskas ${ }^{2}$ \\ ${ }^{1}$ Panevezys Institute, Kaunas University Technology, Lithuania \\ ${ }^{2}$ Faculty of Economics and Management, \\ Kaunas University of Technology, Lithuania
}

\begin{abstract}
Transport is one of the main branches of any economy without which the functioning of a modern economy is, in general, impossible. It ensures necessary economic links and joins all industrial units of a country into one whole, thus establishing the conditions for an economy to function coherently and efficiently. Thus, transport is an important branch of an economy. However, its infrastructure expansion needs high levels of investment. This is why investment projects for the development of the transport structure have to be thoroughly selected and their implementation has to ensure sufficient efficiency. Taking into account that transport generates a number of adverse effects from both transport infrastructures and vehicles, the indirect ones - environmental influences might be included into the group - may have even greater consequences on society than its direct effects.
\end{abstract}

Keywords: environment, assessment, multicriteria analysis.

\section{Introduction}

Transportation systems are linked with a wide range of environmental considerations at all geographical scales, from global warming to local smog and noise. The nature of these environmental impacts is related to the transport modes themselves, their energy supply systems, their emissions and the infrastructures over which they operate. While consuming large quantities of energy, especially oil, vehicles also emit numerous pollutants such as carbon 
dioxide, nitrogen oxide and noise, and transport infrastructures have damaged many ecological systems. Many of the environmental impacts of transport systems have been externalized, implying that the benefits of mobility are realized by a few while the costs are assumed by the whole society. The spatial structure of economics activities, notably their land use, is also increasingly linked with environmental impacts. Taking into account the scale and scope of transport corridors one might assume this to be just conjectured. However, the recent popular techniques (usually cost-benefit analysis) enabling to rank transport projects and the practice of recognizing them to be functional in both economic and social terms - do not cover all the nominated impacts. The authors of the article consider this practice to be limited and support the idea of employing the principles of multicriteria analysis as a practical tool for assessment the impact of transport corridors on the environment.

\section{The concept of a transport corridor}

There is no basis in scientific theory for the corridor approach. In contrast, there are numerous examples of, as well as practical experience with, the use of a corridor approach in, admittedly, widely varying contexts where in most cases the aim is to resolve a specific problem of co-operation between partners developing links along a given corridor in which they have a shared interest; a certain pragmatism always lies behind the original decision to promote a corridor. With the enlargement of the European area, this practical experience with corridors developed into more formal arrangements as well as agreements between national and international institutions. The outcome is that experience with a given corridor has not always proved beneficial in the development of subsequent corridors, given the degree to which the particular context, objectives and partners involved can vary from one project to another (Parker [1]). However, the concept of a transport corridor is directly connected with the processes of transport planning.

To take an example from the more recent past, one of the first projects to leave a mark on transport planning was the development of the North-Eastern corridor in the United States during the 1960s. The North-Eastern corridor, which runs from North of Boston to South of Washington D.C., was designed to address major congestion problems arising from high rates of traffic growth that were a major source of concern for the future of the United States; the aim was to adopt a long-term approach to infrastructure development, traffic allocation and modal split (Parker [1]). The "strip" of national territory analyzed was relatively wide and provided a framework in which to simulate possible transfers and allocation of traffic between routes, particularly passenger traffic. In this particular case, the concept of "corridor" was defined in particularly broad terms in that it was used to refer to the general alignment of international traffic flows within the European area. These projects were not of an overtly political nature and mainly involved national research agencies and study centers, even though the long-term objective was, indeed, to help bring countries closer together, 
strengthen co-operation, facilitate trade and provide better co-ordination of policies and investment. Finally, the most important initiative involving a corridor approach was set against the highly politicized background of the early stages in the process of opening-up to Eastern Europe in Prague in the framework of the first and following Pan-European Transport Conferences (1991, 1994, 1997). At present the most actual discussions on the corridors concept are hold in the developing countries seeking to substantiate the expediency of huge investment into the poor infrastructure. Such questions as link between transport corridors and economic development issues, environmental and social impacts are the key point of the discussion on the topic.

Anyway, in very general terms the corridor approach can be said to be a product first of a need to globalize, to have a more general approach to transport more closely aligned to not only economic activity but also the need to be operational, to take practical action; there is a "decision-making aspect" to the corridor approach and because of this what might even be termed an institutional dimension. The corridor concept occupies a slightly intermediate and more operational position between evaluation of a project whose framework is too restricted and evaluation of policy towards transport networks where the interactions are too complex to understand and use as a basis for deriving an operational approach. The corridor concept therefore becomes a kind of bridge between local and global constraints in the communications area, between individual and collective decisions, between modal and intermodal approaches, between short-term and long-term decisions, all different facets of the diversity of experiences (Hey et al. [2]).

\section{The practice of assessing transport projects: problem formulation}

Taking into account the complexity of transport corridors and the range of effects - here environmental ones are included as well-generated it must be concluded that the question of corridor project assessment still remains one of the most complicated ones. Practice shows that at presents the macroeconomic evaluation of transport infrastructure projects - even such large-scaled as a corridor - is performed using almost the most popular tool cost-benefit analysis (COBA).

The process of judging whether or not a project should be accepted is called project evaluation. COBA is the examination of a decision in terms of its consequences or costs and benefits. In the context of project evaluation, a costbenefit analysis test is a simple decision rule that consists of accepting only those projects that make a positive profit. In order to evaluate a project from the point of view of its consequences, it is crucial to have a model that predicts the total effect on the state of the economy of undertaking a particular project. This total effect involves a comparison of the economy "with" the project and the economy "without" it. Formally, we embody the relationship between a project and its consequences in the notion of a "policy", i.e. a rule that associates a state of the economy with each public production plan (Kampf [3] and Reynaud [4]). Assessment, qualification and determination of a single factor are subsequently 
divided in two cases. In the first case the project will be implemented and in second case it will not. The difference lies in the evaluation of operating costs and infrastructure service costs. Some of the presented variants will drop out after the implementation of basic evaluation. So we do not take them into account in the next step. But this analysis does not assess just monetary impacts from contribution and a costs perspective. It also takes non-monetary impacts into account. These impacts are estimated either by conversion to financial units (conversion on the basis of a chosen key) or on the basis of evaluation by a set scale beforehand, which must be used again for all rated alternatives by the same procedure. Stressing that, despite the efforts to limit the impact of transport on the environment - this is one of the reason the corridors are formed - the fleet in the corridors generate traffic, at the same time it impacts on the environment through pollution from engine exhaust gases, particularly in urban areas. Plants, animals and habitats are sensitive to the pollutants. For example, nitrogen oxides from exhausts form acid rain in the atmosphere that can damage the trees and soil. Vehicles also release greenhouse gases to the atmosphere that contribute to climate change, although air transport is growing rapidly and may impact on air quality in the future.

Transport also affects the environment in other ways. Land and habitats are lost when new roads are built. Oil slicks from wrecked tanker ships can damage the marine environment and a sustainable transport policy means automatically an overall all-mode transport and energy policy. A sustainable transport policy is always related to the broader policy of general sustainability. Accordingly, the shared effects of transport policy measures in other areas, i.e. 'secondary benefits' and trade-offs, must be taken into consideration. Since any sustainability policy has the risk of being misguided for an environmental policy under a fashionable new title, it is important to continually highlight the importance of the socioeconomic dimension, not forgetting to involve citizens and business community in an early stage. The new credo must become 'creating instead of compensating', meaning that companies should invest in innovations (jobs) in front of their own door, instead of trading with $\mathrm{CO}^{2}$ rights by 'planting trees' in third-world countries only etc.

So these examples let us conclude that cost-benefit analysis might be considered to be too small - scaled tool for decision making in the planning and / or maintaining such large infrastructure objects as transport corridors. Ignorance of the issues enables the decision makers to dismiss the most important effects and to take, maybe, not the best solution (for the society) in solving most economic, social or environmental problems. The recourse here could be the application of multicriteria analysis, which could be used for exploiting the preferences of decision-makers, stakeholders, or environmental experts (in the following simply referred to as "stakeholders") to derive monetary values for impacts whose monetization has remained problematic. The ultimate goal is to integrate multicriteria methodology into the wider frame of cost-benefit analysis (CBA) for supporting policy and decision-making, especially in the context of sustainable development [6]. 


\section{Principal issues on multicriteria analysis}

Multicriteria analysis (MCA, also known as multi-attribute analysis, multi-goal analysis and multicriteria decision making) is a two-stage decision procedure. The first stage identifies a set of goals or objectives and then seeks to identify the trade-offs between those objectives for different policies or for different ways of achieving a given policy. The second stage seeks to identify the 'best' policy by attaching weights (scores) to the various objectives. As most authors do conclude that MCA is especially widely used in the Netherlands. Multicriteria analysis appeared in the 1960s as a decision-making tool. It is used to make a comparative assessment of alternative projects or heterogeneous measures. With this technique, several criteria can be taken into account simultaneously in a complex situation. The method is designed to help decision-makers to integrate the different options, reflecting the opinions of the actors concerned, into a prospective or retrospective framework. Participation of the decision-makers in the process is a central part of the approach. The results are usually directed at providing operational advice or recommendations for future activities.

MCA has undergone an impressive development during the last 30 years, in part because it is amenable to handling today's complex problems in which the level of conflict between multiple evaluation axes is such that intuitive solutions are not satisfactory. MCA is not a tool providing the 'right' solution in a decision problem, since no such solution exists. The solution provided might be considered best only for the stakeholders who provided their values in the form of weighting factors, while other stakeholders' values may indicate another alternative solution. Instead, it is an aid to decision-making that helps stakeholders organize available information, think on the consequences, explore their own wishes and tolerances and minimize the possibility for a post-decision disappointment. The purpose of the tool is to structure and combine the different assessments to be taken into account in decision-making, whereby decisionmaking is made up of multiple choices and the treatment given to each of the choices condition the final decision to a large extent. The choice of the authors of using MCA for evaluation the impact of transport corridors on environment could be illustrated by the results of deep research of different authors environmentalists (Hey et al. [2], Pearche and Hett [6], Inception Report [7]). Summarizing their findings concerning (see Table 1) evaluation methods of transport on environment we do present, which do support our choice of employing MCA in our investigation. $\mathbf{V}$ shows cases where a tool is relevant to a stage of the framework (even if relevance is very limited), VV shows the stages that the outputs of each tool are most concerned with. Furthermore, we do conclude that the sequence of the effects valued could be illustrated by the example and must be corrected according each situation (in evaluation process of transport corridors' impact on environment): starting with a Demand/Driver (e.g. for nitrogen fertilizers); which causes a Pressure (formation of nitrates that are leached); resulting in a State (increased amounts of nitrates in drinking water); which has an Impact (adverse health outcomes); requiring a Response (e.g. limit 
Table 1: Comparison of individual tools for evaluating the environmental effects of transport.

\begin{tabular}{|l|c|c|c|c|c|c|}
\hline & $\begin{array}{c}\text { Sustain- } \\
\text { ability } \\
\text { indicators }\end{array}$ & $\begin{array}{c}\text { Life } \\
\text { cycle } \\
\text { assessment }\end{array}$ & $\begin{array}{c}\text { Multi- } \\
\text { criteria } \\
\text { analysis }\end{array}$ & $\begin{array}{c}\text { Cost } \\
\text { effectiveness } \\
\text { analysis }\end{array}$ & $\begin{array}{c}\text { Impact } \\
\text { pathway } \\
\text { analysis }\end{array}$ & $\begin{array}{c}\text { Cost- } \\
\text { benefit } \\
\text { analysis }\end{array}$ \\
\hline $\begin{array}{l}\text { Demand } \\
\text { Driver }\end{array}$ & $\mathrm{V}$ & $\mathrm{V}$ & $\mathrm{V}$ & $\mathrm{V}$ & - & - \\
\hline Pressure & $\mathrm{VV}$ & $\mathrm{VV}$ & $\mathrm{V}$ & $\mathrm{V}$ & $\mathrm{V}$ & - \\
\hline State & $\mathrm{VV}$ & $\mathrm{V}$ & $\mathrm{V}$ & $\mathrm{V}$ & $\mathrm{V}$ & \\
\hline Impact & - & $\mathrm{V}$ & $\mathrm{V}$ & & $\mathrm{VV}$ & - \\
\hline Response & - & $\mathrm{V}$ & $\mathrm{VV}$ & $\mathrm{VV}$ & - & $\mathrm{VV}$ \\
\hline
\end{tabular}

fertilizer use or water purification). This front-to-back structure links all the elements in the decision-making process, is an important feature that prompts users to consider the wider context.

\subsection{How the mechanism works}

The main steps involved in multicriteria analysis can be broken down into several phases described chronologically below. It is possible to repeat the phases and thus to make corrections.

Phase 1. Definition of the projects or actions to be judged, setting the targets.

This will involve an inventory of the planned or implemented actions, or the elements on which the comparative judgment will be made.

Phase 2. Definition of judgment criteria.

Particular attention must be given to the definition of criteria, in order to be as exhaustive as possible and to define the question properly. The criteria must reflect the preferences of the decision-makers or the different points of view so as to summarize and group together diverse characteristic dimensions used to evaluate an action. In the case of European Union socio-economic programs, the success of a measure is normally judged in terms of its contribution to the achievement of the intermediate objectives stated in the programming documents. The main European Union policy priorities (e.g. environment, equal opportunities) are also judgment criteria. A variant consists of relying instead on the implicit objectives of the program, reconstructed by the steering group or extended work groups, e.g. with the aid of the concept mapping of impacts. If the evaluation were intended to focus primarily on the relevance of the program to the regional economy rather than the impacts, the multicriteria analysis would concentrate on the main strengths and weaknesses of the regional economy and the way in which the different measures build on strengths or offset weaknesses.

The synergy between the impacts of the different measures could also be considered, and if so 'synergy' would become a judgment criterion in its own right. It is possible to use a matrix of cross impacts and, in particular, coefficients of synergy for taking this criterion into account in the formulation of a 
synthesized judgment on the measures. In the case of European Union socioeconomic programs, the success of a measure is normally judged in terms of it contribution to the achievement of the intermediate objectives stated in the programming documents. The main European Union policy priorities (e.g. environment, equal opportunities) are also judgment criteria. A variant consists of relying instead on the implicit objectives of the program, reconstructed by the steering group or extended work groups, e.g. with the aid of the concept mapping of impacts [5].

Unlike the number of measures to be compared, which can be very large, the number of criteria must not exceed a reasonable limit. Experience has shown that the maximum number of criteria for an effective evaluation is eight criteria.

Compensation method. The compensation method is the best-known variant and consists of attributing a weight to each criterion and then of calculating a global score for each measure, in the form of a weighted arithmetic average of the scores attributed to that measure for the different criteria. This variant is called "compensatory" because the calculation of the weighted average makes it possible to compensate between criteria. For example, a measure that had a very bad impact on the environment could still obtain a good global weighted score if its impact on employability were considered excellent.

Outranking method. The outranking variant is used where the criteria are not all considered commensurable, and therefore no global score can be produced. The analysis is based on multiple comparisons of the type: "does Measure A outrank Measure B from the point of view of the environment criterion?", "does Measure A outrank Measure B from the point of view of the employability criterion?", etc. These questions can be answered yes or no or be qualified, in which case the notions of a weak preference and a threshold criterion are introduced. The analysis makes all possible comparisons and presents a synthesis of the type: "Measure A is at least as good as Measure B, in relation to a majority of criteria (case of agreement), without being altogether too bad in relation to the other criteria (case of disagreement)" [5].

The analysis could include protection against a favorable judgment for a measure that would be disastrous from the point of view of the given criterion, by setting a 'veto threshold' for each criterion. The introduction of a veto threshold strongly differentiates the logic of outranking from the logic of compensation. If there were a veto threshold, a very bad impact on the environment would make it impossible to consider the measure good, even if its impact on employability were considered excellent.

Outranking has the advantage of reflecting the nature of relations between public institutions better, since there is often a correspondence between evaluation criteria and evaluation stakeholders. In cases where the steering group is extended to about ten partners, it is not unusual for participants to identify themselves strongly with the "environment" or "employment" criteria. In this situation the outranking variant will probably better reflect the collective process of formulating a judgment within the steering group. 
Phase 3. Creating a decision matrix

It's critical to rate solutions based on a ratio scale and not on a point scale. For instance, the ratio scale could be $0-5,0-10$, or $0-100$. Should you feel you must use a point scale (for instance, maximum speed, temperatures, etc.), you must then convert rating values on a ratio scale by assigning the maximum ratio to the estimated maximum value, which could be, for instance, 5 (for a 0-5 scale), 10 $(0-10)$, or $100(0-100)$. Indeed, a point scale with high values introduces a bias even if it's of less importance in the final decision. The demonstration how the process of evaluation goes might be illustrated by the example as follows presented by [5]. The information was included into a decision matrix as shown below, and then the scores were computed for each solution regarding the criteria with eqn (1) below:

$$
\sum_{n=1}^{j} W=P_{j} \times W_{j}
$$

where $\sum_{n=1}^{j} W-$ total score (sum of scores) so called summary value indicator of project or alternative, $P_{j}$ - score of variant x under evaluation criteria $j, W_{j}-$ weight attributed to evaluation criteria $\mathrm{j}$ performance (score) of a project variant $\mathrm{x}$ under evaluation criteria $j$. The result is the following:

Table 2: $\quad$ Assessment of an alternative using MCA.

\begin{tabular}{|l|l|l|l|l|l|l|l|}
\hline \multicolumn{2}{|c|}{} & \multicolumn{9}{|c|}{ Alternatives } \\
\hline \multicolumn{2}{|l|}{ Option A } & Option B & \multicolumn{2}{c|}{ Option C } \\
\hline CRITERIA & Weight & Rating & Score & Rating & Score & Rating & Score \\
\hline Criterion C1 & 1 & 3 & 3 & 3 & 3 & 3 & 3 \\
\hline Criterion C2 & 2 & 2 & 4 & 1 & 2 & 2 & 4 \\
\hline Criterion C3 & 3 & 1 & 3 & 3 & 9 & 2 & 6 \\
\hline Total & 6 & 4 & 10 & 7 & 14 & 7 & 13 \\
\hline
\end{tabular}

When we sum up the ratings, both solutions $\mathrm{B}$ and $\mathrm{C}$ are equivalent and outperforming solution A. While similar globally, options B and C present different intrinsic strengths and weaknesses. Indeed, option $\mathrm{B}$ is better than option $\mathrm{C}$ for the criterion $\mathrm{C} 3$, but weaker on $\mathrm{C} 2$, while option $\mathrm{C}$ distribute more evenly its forces. Therefore, Option B is usually called a best-of-breed solution, while Option $\mathrm{C}$ is a typical suite or integrated solution. The technique was applied for practical purposes: developing the methodological bases for valuation the effects of transport corridors on environment. The principal findings are presented in the following section. 


\subsection{Assessing environmental effects of transport corridors: practical considerations and conclusive remarks}

After the significance of the transport corridors was proved and the methodological principles of MCA analyzed, we tried to use evaluate the impact of several transport corridor projects on environment. However, we faced several important obstacles, but the main of them were:

- There was no consensus on the very concept of a transport corridor: different authors describe these in their own manner and the definition mostly depends on their field of investigation. Furthermore, for the reason, the functions and impacts of the corridors on environment also vary from study to study.

- It was also very difficult to define the set of criteria as the basis to start evaluation. In most academic publications these vary dramatically or are excluded from scope of analysis.

- Evaluating the impact of transport corridors from the environmental perspective, we do stress that the impact is generated no only by so-called roads (railways, motorways, arteries of waterways) but by the infrastructural objects (customs, cafes, filling - stations an etc.). For the reason, impact analysis becomes very complex.

- The performance of infrastructure and its measurement still remains under the academic discussion.

All the aforementioned aspects enabled us to state, that despite the wide opportunities of MCA, the COBA principles so widely in practice employed in decision-making processes a simple decision rule should not be neglected because it allows one to accept only those projects that make a positive profit. But because the concept "profit" or better to say "benefit" in public terms is understand much wider (as it was discusses in section 3), the scope of this classic tool must be expanded and supplemented by MCA principles. Stating "principles" we do conclude that measurement of transport corridors' impact on environment in our point of view could be assessed employing several aspects of MCA. The reason here is above stated problems. Recognizing, that after detailed investigation the scientists and patricians will come to the conclusion and will propose the proper methodology and the list of assessment criteria in the nearest future, however, the development processes of corridors are very intensive not only in ambitious EU, but in most developing countries. So the methodological framework of impact assessment is extremely required, because a great danger in complex analysis arises if tools are wrongly applied - this undermines the whole result. Envisaging several serious shortcomings of MCA (no clear criteria for selecting impacts, risk of double counting impact categories, potential for arbitrariness in ordinal scoring of qualitative impacts, potential for arbitrariness in weighting overall impacts for relative importance) we do correct the standard procedures under the following assumptions (these are summarized in fig. 1):

Phase 1. Definition of the project and setting the targets. Complex investigation of possible project impacts on environment, scoping overall infrastructure influence. 
Phase 2. Making a list of possible environmental impacts conditionally treating these as assessment criteria of impact performed. Selecting a steering group of experts for making a decision which impacts must be considered (as the most important) in further assessment process and as supporting tool for final solution. Weighting the impacts in the list and testing the concord of the experts by calculating the Kendal's concordat ion coefficient. In the case it is reasonable, rating the impacts and scoring them.

Phase 3. Creating a decision matrix as additional tool for final solution and combining the results with the outcomes from COBA. The example of expanded solution matrix is presented in Table 3.

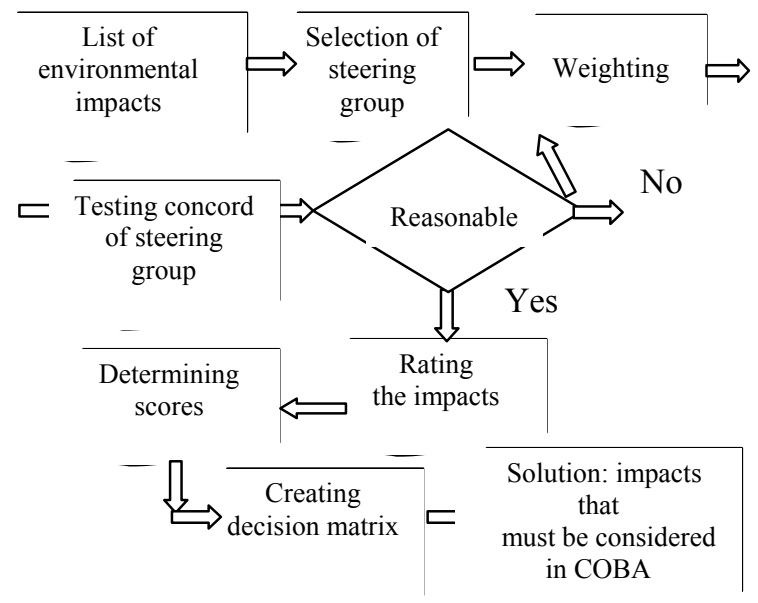

Figure 1: $\quad$ Principle structure of the evaluation procedure.

Table 3: $\quad$ Assessing corridor projects: integration of COBA and MCA.

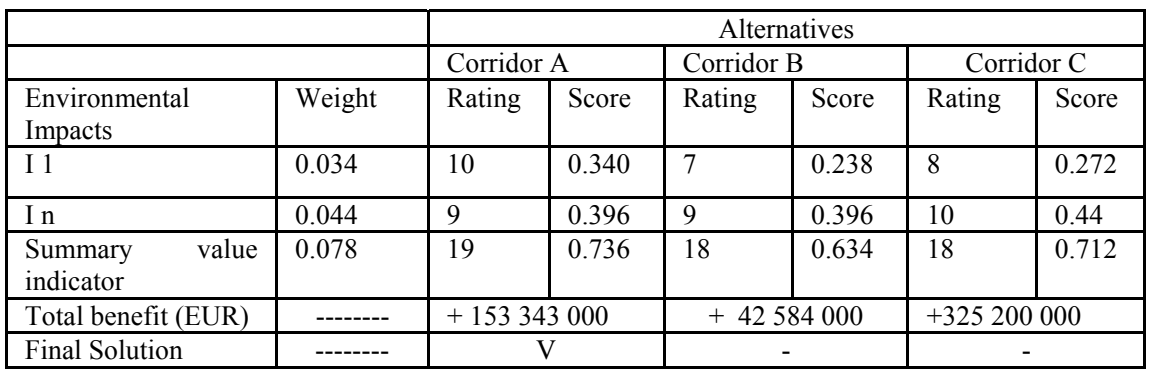


The method proposed was tested empirically but because of limited space in this paper are not presented. Indeed, its purpose is to try to identify what environmental impacts of corridors are, and how these can be 'captured' within a corridor appraisal framework. We do conclude that the method may and even should be improved, but the principal ideas must not be neglected.

\section{References}

[1] Parker J. A Charetteon Florida's Future New Corridors. Online http://www.ftc.state.fl.us

[2] Hey C. et al. Assessing Scenarios on European Transport Policies by means of Multicriteria Analysis. Online http://www.tinbergen.nl/97086.pdf

[3] Kampf R. The Macroeconomic Evaluation of Transport Infrastructure Projects. Online http://fpedas.uniza.sk/dopravaaspoje/2005/1/kampf.pdf

[4] Evaluating Socio Economic Development. Online http://books.google. $\mathrm{com} /$ books

[5] Diakoulaki D, Grafakos S. Multicriteria analysis. Online www.externe.info

[6] Pearche D. \& Hett T. Review of Technical Guidance on Environmental Appraisal. A Report by ERFTEC (Economics for the Environment Consultancy). Workshop at Environment Centre of Charles University in Prague: pp. 3-7, 1999.

[7] Framework for the inclusion of social benefits in transport planning. Inception Report. Unpublished Project Report No PR/INT/262/03. University of Birmingham. Online. http://www.transportlinks.org 